\title{
Snow-mediated plasticity does not prevent camouflage mismatch
}

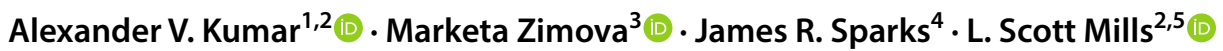

Received: 6 December 2019 / Accepted: 3 June 2020 / Published online: 24 June 2020

(c) The Author(s) 2020

\begin{abstract}
Global reduction in snow cover duration is one of the most consistent and widespread climate change outcomes. Declining snow duration has severe negative consequences for diverse taxa including seasonally color molting species, which rely on snow for camouflage. However, phenotypic plasticity may facilitate adaptation to reduced snow duration. Plastic responses could occur in the color molt phenology or through behavior that minimizes coat color mismatch or its consequences. We quantified molt phenology of 200 wild snowshoe hares (Lepus americanus), and measured microhabitat choice and local snow cover. Similar to other studies, we found that hares did not show behavioral plasticity to minimize coat color mismatch via background matching; instead they preferred colder, snow free areas regardless of their coat color. Furthermore, hares did not behaviorally mitigate the negative consequences of mismatch by choosing resting sites with denser vegetation cover when mismatched. Importantly, we demonstrated plasticity in the initiation and the rate of the molt and established the direct effect of snow on molt phenology; greater snow cover was associated with whiter hares and this association was not due to whiter hares preferring snowier areas. However, despite the observed snow-mediated plasticity in molt phenology, camouflage mismatch with white hares on brown snowless ground persisted and was more frequent during early snowmelt. Thus, we find no evidence that phenotypic plasticity in snowshoe hares is sufficient to facilitate adaptive rescue to camouflage mismatch under climate change.
\end{abstract}

Keywords Adaptive rescue $\cdot$ Phenotypic plasticity $\cdot$ Behavioral plasticity $\cdot$ Climate change $\cdot$ Molt phenology

\section{Introduction}

The detrimental effects of climate change on the fitness of wild populations may be ameliorated by adaptation (Hoffmann and Sgró 2011). Local adaptation to rapid environmental change may occur through both evolution via natural selection (i.e., evolutionary rescue (Vander Wal et al. 2013)) and phenotypic plasticity (Ghalambor and Martin 2001). Although both mechanisms are possible and can interact

Communicated by Janne Sundell.

We demonstrate that snow itself can directly affect phenotypic plasticity. We also connect this plasticity to adaptive rescue in a charismatic and topical system: climate change effects on hares.

Electronic supplementary material The online version of this article (https://doi.org/10.1007/s00442-020-04680-2) contains supplementary material, which is available to authorized users.

Alexander V. Kumar

avk36@cornell.edu

Extended author information available on the last page of the article
(Forsman 2015), phenotypic plasticity may provide the most rapid adaptive response in the face of climate change (Gienapp et al. 2008; Beever et al. 2017; Snell-Rood et al. 2018). Climate change-induced plasticity in the timing of life history events has been demonstrated in various taxa including amphibians (Parmesan 2007), butterflies (Parmesan 2007), birds (Przybylo et al. 2000), and mammals (Ozgul et al. 2010; Lane et al. 2012). However, the scope for plastic responses to maintain fitness under climate change is largely unknown.

Climate change can affect seasonal phenological processes through shifts in abiotic drivers such as temperature (Both and Visser 2001; Kudo and Ida 2013) and precipitation (both rain (Penuelas et al. 2012; Cohen et al. 2018) and snow (Sheriff et al. 2011; Lane et al. 2012; Rickbeil et al. 2019)). Snow is particularly relevant because a reduction in number of days with snow cover is one of the most consistent and widespread signals of climate change in the northern hemisphere (Pederson et al. 2011; Kunkel et al. 2016; $\mathrm{Zhu}$ et al. 2019). Snow declines have a direct impact on organisms adapted to seasonal environments (Williams et al. 
2015; Hock et al. 2019; Shipley et al. 2019), including a diverse group of birds and mammals that molt from summer brown to winter white annually to increase crypsis against snow (Mills et al. 2018; Zimova et al. 2018). For these species, reduced snow duration can increase camouflage mismatch, a striking and direct climate change stressor (Mills et al. 2013, 2018), which results in white animals suffering higher predation rates against a dark snowless background (Zimova et al. 2016; Atmeh et al. 2018; Wilson et al. 2018).

The snowshoe hare (Lepus americanus), an important prey species for a plethora of carnivores including Canada lynx (Lynx canadensis), undergoes coat color molts across most of its range (Nagorsen 1983; Jones et al. 2018; Mills et al. 2018). Snowshoe hares experience $7-12 \%$ reductions in weekly survival when their coat color is mismatched against the background color (Zimova et al. 2016; Wilson et al. 2018). These fitness costs of camouflage mismatch are sufficient to cause severe population declines in absence of future adaptive responses (Zimova et al. 2016). In fact, hares have already experienced range contractions linked to reduced snow duration and mismatch-related mortality (Burt et al. 2017; Diefenbach et al. 2016; Sultaire et al. 2016).

Plasticity in both molt phenology and in behaviors may reduce or eliminate the fitness costs to mismatched hares. The initiation of the seasonal color molts is largely driven by photoperiod (Lyman 1943) with potential plasticity in the population molt rate modulated by temperature and snow (Zimova et al. 2018). The modulating effect of temperature on seasonal color change in several species has been repeatedly demonstrated in laboratory (Rothschild 1942; Rust 1962) and field settings (Watson 1963; Flux 1970; Zimova et al. 2014, 2020a; Kumar 2015), although its physiological mechanism or fitness consequences are unknown. Whether or how snow can modify molt phenology is much less clear (Grange 1932; Jackes and Watson 1975; Nagorsen 1983; Zimova et al. 2014).

Snow may affect molt phenology indirectly via temperature or directly via light-mediated hormone shifts. Snow may influence temperature by creating a warmer, more thermally stable subnivium space (Goodrich 1982; Pauli et al. 2013) or by its high albedo lowering temperatures (Namias 1985; Choi et al. 2010). The direct physiological effects of snow on molt phenology may occur if light reflected off snow mediates melatonin levels through the same neuroendocrine pathway that regulates photoperiodic systems (Goldman 2001; Schwartz et al. 2001). Although snow has not been definitively linked to molt phenology, it is known to influence other phenological processes such as hibernation (Sheriff et al. 2011; Lane et al. 2012), reproduction (Liebezeit et al. 2014) and migration (Rickbeil et al. 2019).

In addition to plasticity in phenology, animals may directly and rapidly adapt to climate change through other types of behavioral plasticity (Beever et al. 2017; Zimova et al. 2018; Stevens and Ruxton 2019). For seasonally color molting species, plasticity in behaviors may reduce camouflage mismatch per se, or reduce the fitness consequences of mismatch. In a classic example of behavioral plasticity to minimize mismatch, molting ptarmigan (Lagopus lagopus) preferentially forage in areas that maximize their crypsis during their color molts (Steen et al. 1992). Other plastic responses might include behaviors such as resting in dense vegetation, where predator detection and capture rates are lower (Ivan and Shenk 2016). Snowshoe hares are capable of exhibiting behaviors to assess and reduce predation risk; for example, under a full moon, hares increase their use of high cover areas (Gilbert and Boutin 1991; Gigliotti and Diefenbach 2018) or decrease their movement (Griffin et al. 2005). Although a general preference for dense cover is a hallmark of snowshoe hare biology (Adams 1959; Wolff 1980; Litvaitis et al. 1985), the two existing studies that examined concealment in relation to mismatch provide contrasting results (Litvaitis 1991; Zimova et al. 2014).

The central aim of this study is to determine the ability and scope for phenotypic plasticity to facilitate adaptive responses to camouflage mismatch. First, we quantified plasticity in color molt phenology of snowshoe hares and the extent to which it is driven by snow cover. We predicted that hares molt to white earlier and faster during snowier falls and become brown later and slower during snowier springs. Second, we tested whether hares exhibit behavioral plasticity through either choice of background to minimize mismatch or choice of habitat structure to increase concealment. Finally, we evaluated whether these possible avenues of phenotypic plasticity are sufficient to reduce the occurrence of camouflage mismatch.

\section{Methods}

\section{Study areas}

Fieldwork for this study was conducted in two areas of the Upper Blackfoot region of western Montana, USA on land managed by the Bureau of Land Management; see (Kumar et al. 2018) for details. Marcum Mountain (Lat. $=46.99^{\circ}$, Long. $\left.=-112.91^{\circ}\right)$ and Chamberlain Creek (Lat. $=46.96^{\circ}$, Long. $=-113.24^{\circ}$ ) are approximately $30 \mathrm{~km}$ apart at similar elevations (approximately 1450-1700 m.a.s.l.). Both areas have dominant tree species of western larch (Larix occidentalis) (approximately $25-50 \%$ of total stems) interspersed with Douglas fir (Pseudotsuga menziesii), subalpine fir (Abies lasiocarpa), lodgepole pine (Pinus contorta) and Engelmann spruce (Picea engelmannii) and an herbaceous understory. For the analysis on the influence of snow on molt phenology only, we also used data previously collected at two additional study sites: (1) Seeley was approximately 
$40 \mathrm{~km}$ away with similar vegetation types and elevation (1400 m.a.s.1.) (Mills et al. 2013; Zimova et al. 2014), (2) Gardiner was approximately $300 \mathrm{~km}$ away at about twice the elevation (2400-2700 m.a.s.l.) with cooler temperatures and longer durations of snow cover (Zimova et al. 2014). Likely predators of snowshoe hares at all sites include Canada lynx, bobcat (Lynx rufus), cougar (Puma concolor), coyote (Canis latrans), red fox (Vulpes vulpes), American marten (Martes americana), long-tailed weasel (Mustela frenata), golden eagle (Aquila chryseatos), great horned owl (Bubo virginianus), barred owl (Strix varia), northern goshawk (Accipiter gentilis), and red-tailed hawk (Buteo jamaicensis).

\section{Capture/handling}

We live-trapped snowshoe hares during fall 2012 and summer and winter 2013-2014 using live traps $(51 \times 18 \times 18 \mathrm{~cm}$, Tomahawk Live Trap Company, Tomahawk, WI) baited with alfalfa cubes and apples. We marked all hares $>500 \mathrm{~g}$ with a unique numbered ear tag and a VHF radio-collar (Wildlife Materials, Murphysboro, IL) weighing $<40 \mathrm{~g}$. All capture and handling procedures were approved by the University of Montana Animal Care and Use Committee (permit no. AUP 021-13SMECS-050613).

\section{Snowshoe hare molt phenology and resting site selection}

Using VHF radio-telemetry, we tracked 49 individual snowshoe hares and obtained 280 locations during the fall brownto-white and the spring white-to-brown molts. We used the VHF signal to visually detect hares during the day (typically between 10:00 and 16:00) usually at a distance of 3-10 m. Observations typically occurred at resting sites, "forms", (94\% of all observations), which usually overlap the habitat used by foraging hares (Ferron and Ouellet 1992; Hodges 2000). We determined if the hare was resting in a form (as opposed to merely transitioning through) by examining their location for an indentation in the vegetation or snow and fresh feces. We followed a standardized protocol of visual observation and photography to estimate hare percent white: $(0 \%, 5 \%, 20 \%, 40 \%, 60 \%, 80 \%, 95 \%$, and $100 \%)$ (Mills et al. 2013). Hare percent white was typically estimated by two observers in the field and, in the cases of uncertainty, a single observer (AVK) used photographs to make the final determination. We considered a hare to be molting when it was $>0 \%$ but $<100 \%$ white.

Each time we located a hare in a form, we recorded associated resting site characteristics. We estimated snow cover at each hare location in $20 \%$ increments as the percent of the ground covered with snow. We measured snow cover at both 1- and 10-m plot radii centered on the hare form to capture different scales at which crypsis may be perceived (Zimova et al. 2014). We computed color contrast (hare percent white - snow cover), and defined mismatch as occurring when the absolute value of color contrast was $\geq 60 \%$ (Mills et al. 2013). We further differentiated mismatch between white hares found on brown snowless backgrounds (white hare mismatch) and brown hares found on snowy backgrounds (brown hare mismatch). We recorded the temperature at the hare form with a handheld weather meter (Kestrel 2000, Nielsen-Kellerman, Boothwyn, PA). We used a circular plot of 5-m radius centered on the hare form to quantify the total number of stems ( $>1 \mathrm{~m}$ tall and $>2.5 \mathrm{~cm}$ diameter at breast height) of all trees and shrubs (Lewis et al. 2011; Kumar et al. 2018).

We used a paired, used-available design to (1) test for the ability of hares to minimize mismatch or increase concealment and (2) unravel a causal (snow influencing the molt) relationship versus a correlative one (white hares preferring snow). We paired each hare location (used) with an available location in a random direction and distance (weighted by hare home range size, see Appendix S1) from each hare location. We recorded snow cover, temperature and stem counts at each available point immediately after sampling the paired used point.

\section{Statistical analyses}

We used mixed-effect models using package "Ime4" (Bates et al. 2015) in Program R (version 2.15.1, R Development Core Team 2012) to evaluate snowshoe hare molt phenology association with snow and hare resting site selection. We standardized all predictors to a mean of 0 and a standard deviation (SD) of 1 to facilitate comparisons between models; when predictors were strongly correlated $(>0.7)$, we included only the predictor that best fit the data using a linear model (Dormann et al. 2013). Because all the predictors were biologically informed, we only ran the full models (Bolker et al. 2009), which included the response and all uncorrelated fixed and random effects. For comparison purposes, and to more explicitly consider model fit, we also model averaged by AICc using the full model and all combinations of the reduced models (Appendix S2) and found no major differences in predictor estimates. To help interpret effect sizes, we present effects in terms of how a one SD change in the predictor would affect the response, in addition to providing the predictor means and standard errors.

\section{Snowshoe hare molt phenology}

We quantified hare molt phenology during spring 2013, 2014 and fall 2013 at Marcum and spring 2014 and fall 2013 at Chamberlain (insufficient data prevented estimation of molt initiation and completion dates for some year/site combinations). To accommodate incomplete detection and 
high hare mortality, we used a Bayesian mixed-effect change point analysis to estimate the mean population molt initiation and completion dates (Mills et al. 2013; Zimova et al. 2014). We used a repeated-measures model with individual hare as the random effect to avoid the pseudoreplication that would occur by considering the repeated measures of the same individual as independent samples. The model was fit with Markov Chain Monte Carlo (MCMC) in OpenBugs with uninformative priors. All models were run with five chains of 100,000 iterations (discarding 10,000 burn-ins), with the Gelman-Rubin statistic indicating chain convergence $(\widehat{R} \leq 1.1)$. We calculated initiation and completion dates of the molt and the resultant $95 \%$ credible intervals for each site and season separately. We also estimated area and year specific snow cover by averaging the snow cover estimates taken multiple times a week at used and available sites. We extrapolated estimates for missing days using a moving average yielding daily snow cover estimates (Mills et al. 2013; Zimova et al. 2014).

\section{Snow influence on molt phenology}

We used a mixed-effect modeling approach to evaluate whether snow cover was positively associated with hare percent white during the molt. We included only observations when hares were molting (i.e., 5-95\% white). In addition, for this question only, we were able to add data collected from 2009 to 2012 using the same protocols from other sites in Montana (Mills et al. 2013; Zimova et al. 2014), increasing our sample size to 200 individual hares and 1313 hare locations. We included a fixed effect for date to prevent attributing to snow cover any changes in the hare percent white that were actually due to season (i.e., the occurrence of both white hares and snow is expected to increase over time in the fall). Thus, all seasonal changes were absorbed by the date fixed effect, leaving only daily variation in hare percent white to be explained by the model; though rigorous, this approach will produce smaller effect sizes. Because the fixed effect of date on hare percent white would have a positive slope in the fall and negative slope in the spring, we analyzed spring and fall separately. The full model consisted of hare percent white as the response, fixed effects for date and the standardized measurement of snow cover at $10 \mathrm{~m}$, and random effects for individual hare, year and region.

\section{Hare resting site selection}

We tested for hare resting site selection by fitting a generalized linear model with a binomial distribution to examine the differences between forms used by hares and the paired available locations. The full model consisted of used versus available locations as the response and the standardized measurements of number of stems, temperature at the form, snow at $1 \mathrm{~m}$ and all of their one-way interactions as fixed effects and a random effect for individual hare. We expressed the results as odds ratios on the real scale. We also tested for differences in resting site selection by subsetting the data for instances when hares were mismatched (color contrast $\geq 60 \%$ ) compared to when they matched their background (color contrast $<60 \%$ ).

\section{Results}

\section{Snowshoe hare molt phenology and mismatch}

We found no significant differences (i.e., $95 \%$ credible intervals overlap) in either the estimated initiation or completion dates of snowshoe hare molts between the two study areas during the same season (Figs. 1a, 2a). Consequently, the hare molt duration for both study areas in fall 2013 and spring 2014 was similar: Marcum (36, 40 days) and Chamberlain (40, 39 days). Phenology of snow cover was also similar in both areas in fall (Fig. 1b) and spring (Fig. 2b).

At Marcum, where we monitored molts over two springs, we found significant differences in spring molt phenology between the two years, with each spring molt
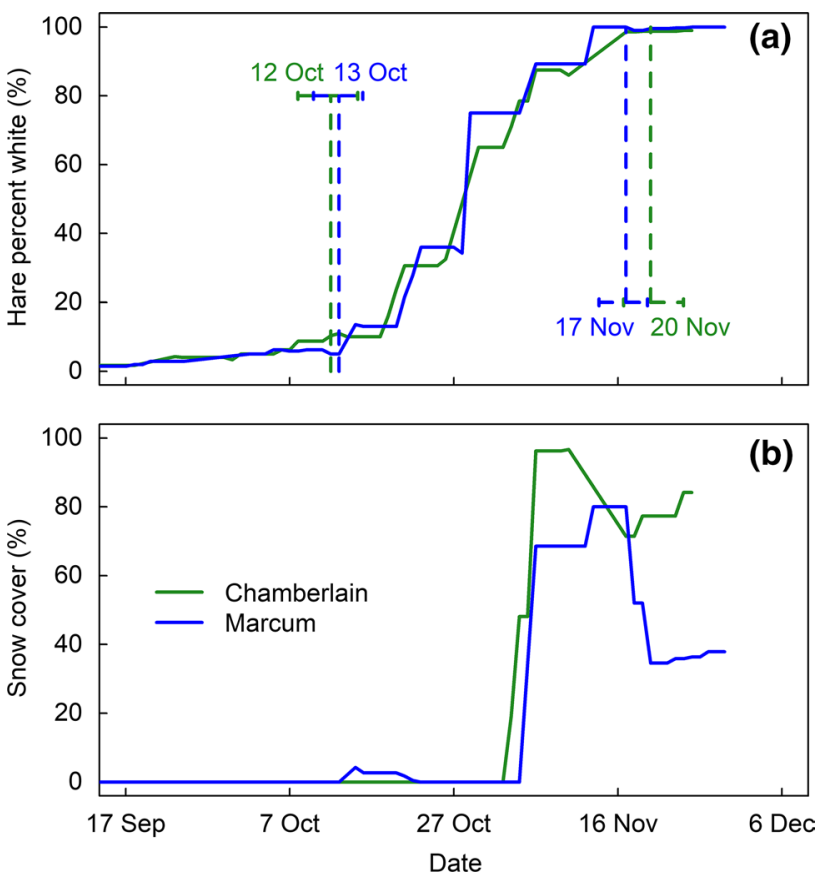

Fig. 1 Fall coat color molt phenology and snow cover in 2013 in two study areas in western Montana, north-central USA. Blue line denotes Marcum study area and green line denotes Chamberlain study area. a Mean weekly coat color of 38 snowshoe hares at two different study areas. Dotted lines indicate mean molt initiation and completion dates and the $95 \%$ credible intervals. b Area-specific averaged weekly snow cover based on a moving average of all 10-m-radius snow cover estimates for each hare per observation 

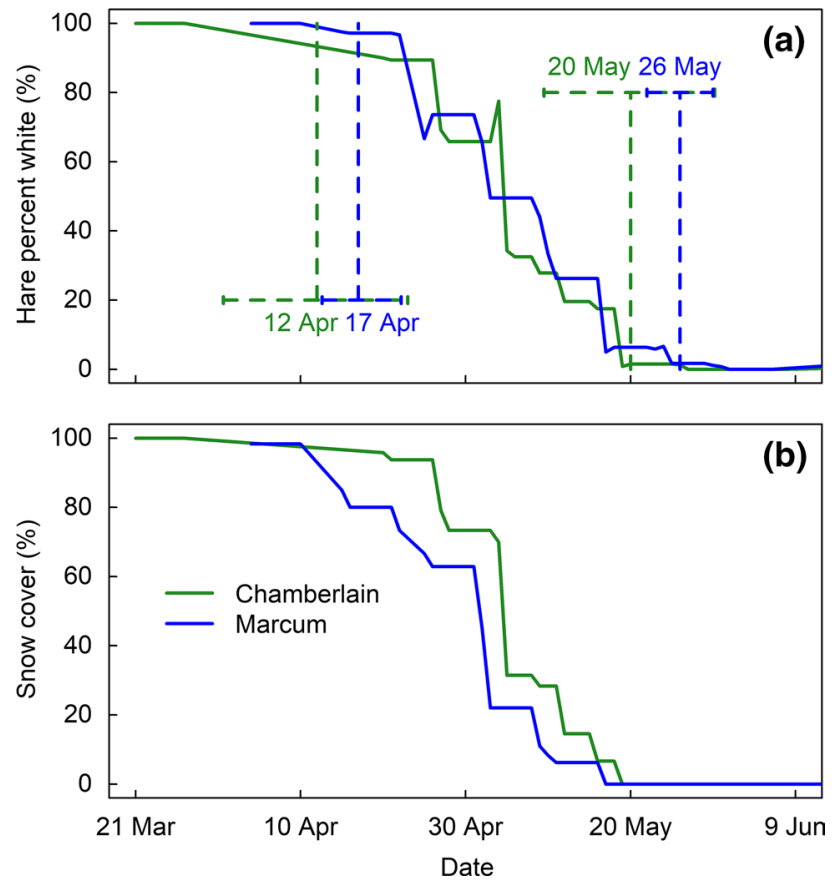

Fig. 2 Spring coat color molt phenology and snow cover in 2014 in two study areas in western Montana, north-central USA. Blue line denotes Marcum study area and green line denotes Chamberlain study area. a Mean weekly coat color of 16 snowshoe hares at two different study areas. Dotted lines indicate mean molt initiation and completion dates and the $95 \%$ credible intervals. b Area-specific averaged weekly snow cover based on a moving average of all 10-m-radius snow cover estimates for each hare per observation

phenology tracking snow cover phenology (Fig. 3). In 2013, hares initiated the molt 20 days earlier than in 2014 and completed 10 days earlier (Fig. 3a). The more rapid molt to brown in 2013 corresponded with a shorter spring snow duration (snow melted earlier and faster in 2013) (Fig. 3b).

Despite the plasticity in molt phenology across years, the earlier snowmelt year of 2013 nevertheless resulted in increased camouflage mismatch. In 2013, we detected 13 occurrences of white hare mismatch (whites hares on snowless backgrounds) and one occurrence of brown hare mismatch (brown hares on snow), based on 56 observations of 15 individuals (Fig. 4a). The 13 occurrences of white hare mismatch were observed in 11 different individuals. By contrast, in the later snowmelt year of 2014, we detected one occurrence of white hare mismatch, based on 57 observations of 8 individuals (Fig. 4b).

\section{Snow influence on molt phenology}

We found a strong effect of snow cover on snowshoe hare molt phenology using data from 200 hares over 6 years, even after controlling for date. An increase of one SD of percent
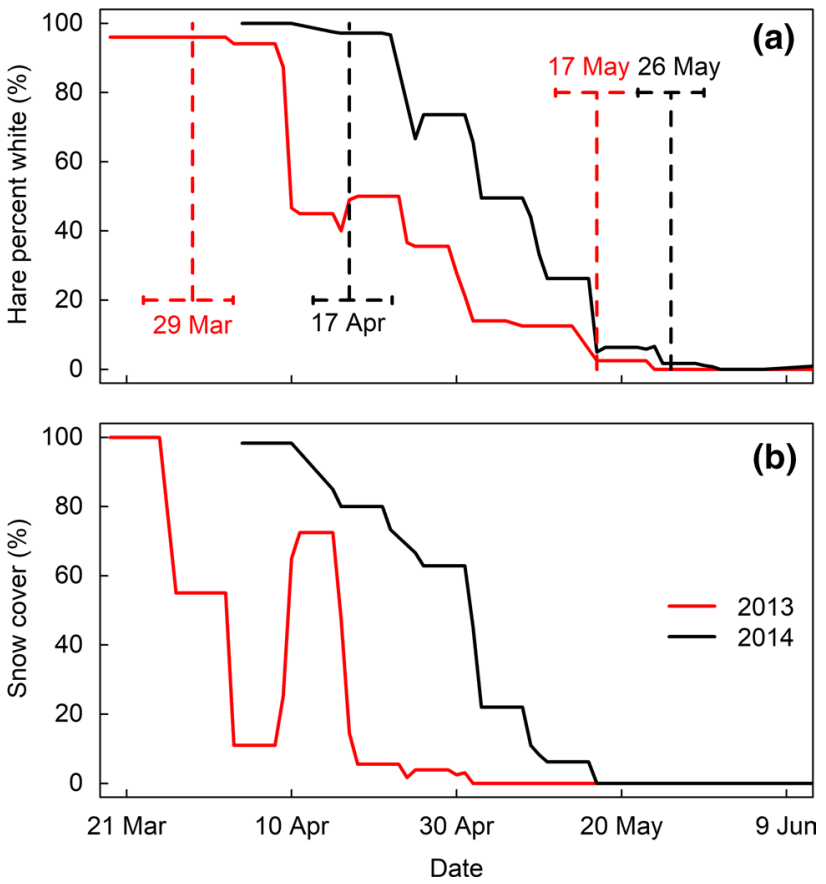

Fig. 3 Shifts in spring coat color molt phenology follow spring snow cover at the Marcum study site. Red line denotes 2013 and black line denotes 2014. a Mean weekly coat color of 23 snowshoe hares. Dotted lines indicate mean molt initiation and completion dates and the 95\% credible intervals. b Area-specific averaged weekly snow cover based on a moving average of all 10-m-radius snow cover estimates for each hare per observation

snow cover (36\% in fall and $44 \%$ in spring) was associated with an increase in hare percent white by $3 \%(\mathrm{SE}=0.8 \%)$ in fall and $11 \%(\mathrm{SE}=1.3 \%)$ in spring.

\section{Hare resting site selection}

Overall, molting hares had strong preference for resting sites with more total stems, less snow cover and colder temperatures (Table 1). An increase in the number of stems by one SD ( 23 stems) increased the odds of hare use by 1.5 times (95\% CI 1.3-1.8). A decrease in percent snow cover by one SD (35\%) increased the odds of hare use by 1.4 times (95\% CI 1.0-1.8). A decrease in temperature by one SD $\left(8.0{ }^{\circ} \mathrm{C}\right)$ increased the odds of hare use by 1.3 times $(95 \%$ CI 1.0-1.5). Whether or not an individual was mismatched did not affect these microhabitat preferences, suggesting a lack of behavioral plasticity to reduce mismatch or its fitness costs. Because hares consistently preferred snow-free (brown) resting sites, we found no evidence that white hares background match via preferentially choosing snowy areas to maintain crypsis. In fact, white hares tend to select resting sites with more bare ground even though brown ground leads to mismatch. Likewise, similar overall preference for resting sites with denser cover (more stems)—regardless of whether 


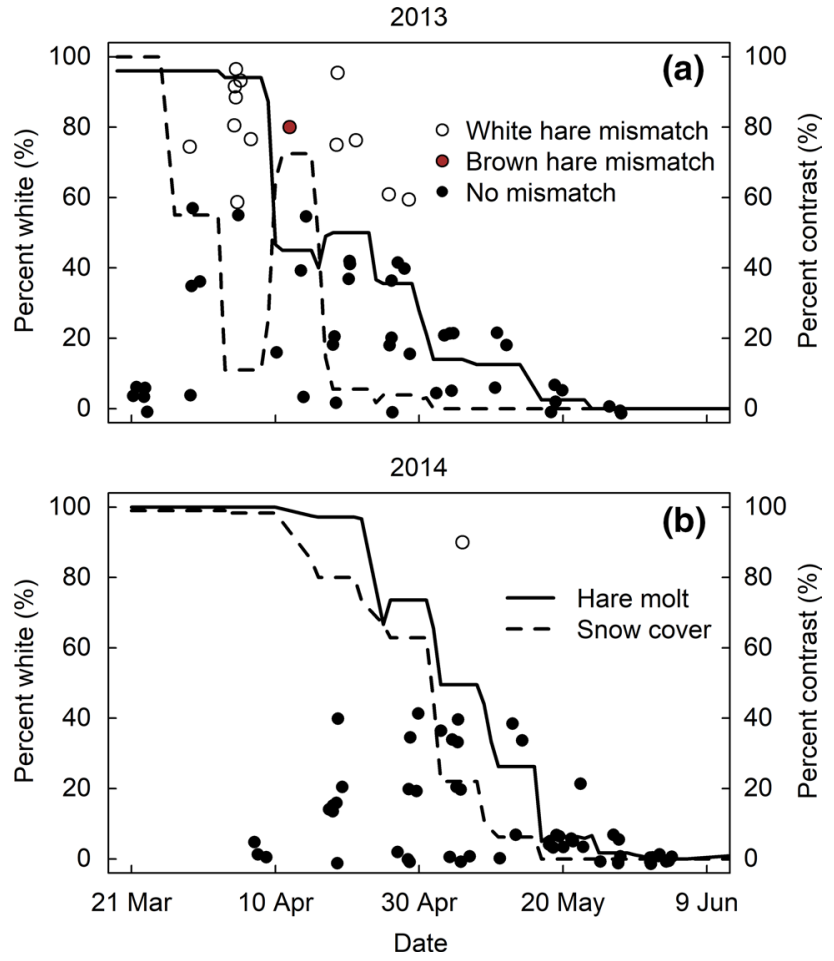

Fig. 4 Early snowmelt results in increased camouflage mismatch in hares in western Montana, north-central USA. a Color contrast and resulting occurrence of mismatch from 56 observations of 15 individuals in 2013 at Marcum study area. Percent white on the $y$-axis represents both hare percent white and percent snow cover at 10 -m-radius. White points indicate white hares mismatched on brown backgrounds, brown points indicate brown hares mismatched on white backgrounds and black points indicate no mismatch. Percent contrast $=$ hare percent white - percent snow cover. Mismatch occurs when contrast $\geq 60 \%$. b Color contrast and mismatch resulting from 57 observations of 8 individuals in 2014 at Marcum study area

Table 1 Snowshoe hare resting site selection in western Montana, north-central USA

\begin{tabular}{lrr}
\hline Predictor & Used (SE) & Available (SE) \\
\hline Number of stems & $35.86(1.23)$ & $26.87(1.24)$ \\
Temperature $\left({ }^{\circ} \mathrm{C}\right)$ & $9.04(0.42)$ & $9.51(0.45)$ \\
Percent snow cover & $12.51(1.58)$ & $22.36(2.09)$ \\
\hline
\end{tabular}

Used sites correspond to locations of hares found in their forms. Each available site corresponds to a random location (Appendix S1). At each site, a 5-m-radius plot was established and total number of stems ( $>1 \mathrm{~m}$ tall and $>2.5 \mathrm{~cm}$ diameter at breast height), temperature and percent snow cover were measured. Mean values of each predictor are given with standard error denoted by parentheses

or not a hare was mismatched-indicated that mismatched hares did not choose microhabitats that potentially provided more protection from predation.

\section{Discussion}

Although phenotypic plasticity can enable rapid adaptation to climate change (Gienapp et al. 2008; Beever et al. 2017; Snell-Rood et al. 2018), ecologists often lack an understanding of mechanisms underlying adaptive phenotypic plasticity, and the extent to which plasticity can reduce or eliminate phenological mismatches between seasonal biotic processes and abiotic climate variables. Focusing on snowshoe hares, a snow-adapted mammal, we provide strong evidence that snow cover drives the observed phenotypic plasticity in molt phenology. However, we also find that this snow-mediated plasticity is insufficient to substantially reduce mismatch between white hares and snowless backgrounds. Furthermore, we find no evidence that snowshoe hares perceive coat color mismatch and adjust their behavior to reduce mismatch or its consequences.

At the Marcum site, where we could follow the spring molt across two years of very different snow duration, we documented phenological shifts in both the initiation and rate of the snowshoe hare spring molt in the direction of annual changes in snow cover (Fig. 3). The much shorter snow duration of 2013 at the Marcum site was corroborated by a nearby weather station (approximately $90 \mathrm{~km}$ away in Missoula) which recorded roughly $25 \%$ lower snow accumulation compared to $2014(123 \mathrm{~cm}$ in $2013,167 \mathrm{~cm}$ in 2014). In that early snow melt year of 2013 , hares began their spring molt almost 3 weeks earlier and became brown about 10 days earlier than in 2014. Accordingly, the 2013 molt took about 50 days, 10 days longer than in 2014 and in other studies (Zimova et al. 2014, 2020a).

In addition to documenting phenological shifts tracking snow cover (Fig. 3), we directly modeled the effect of local snow cover on hare percent white using data spanning 6 years at four study areas separated by up to $300 \mathrm{~km}$, confirming snow as a driver of the observed phenological shifts. The snow effects on molt phenology were evident even after controlling for date, ensuring any changes in the hare percent white were attributable to snow cover and not actually due to season. Importantly, the positive association between snow and hare percent white did not arise from a behavioral preference for snow. On the contrary, snowshoe hares preferred areas with more bare ground, consistent with previous field-based findings at other study sites (Zimova et al. 2014). Thus, associations between snow and hare percent white arise from snow directly affecting hare molt phenology as opposed to behavioral plasticity of white hares preferring snowy areas. Therefore, our findings imply that while photoperiod is the core modulator of the seasonal color molt, snow presence per se may facilitate plasticity in spring molt phenology, perhaps via the same neural 
pathways that perceive changes in photoperiod (Goldman 2001; Schwartz et al. 2001).

Although we established snow-driven plasticity in hare molt phenology, we found no evidence of behavioral plasticity to choose resting areas that reduce coat color mismatch or the associated increased predation risk. We found that regardless of coat color or mismatch, hares preferred areas with no snow and resting sites with dense stems. Thus, hares do not preferentially choose to background match when snow is patchy, or reduce the negative survival costs of mismatch (Zimova et al. 2016; Wilson et al. 2018) through increased concealment. The lack of plasticity to increase concealment when mismatched is consistent with a field study using similar methods to ours with radio-collared hares (Zimova et al. 2014). By contrast, another study that examined hare distributions using baited live traps found that mismatched hares were more often trapped in areas with denser cover (Litvaitis 1991). Hare overall preference for areas with more stems is likely due to the predation protection it affords (Ivan and Shenk 2016); however, the reason hares prefer non-snowy areas is unknown. Possible explanations for hare preference for bare ground include locomotive efficiency and thermoregulatory constraints.

Consistent with thermoregulation influencing hare site selection, we found support for hare preference of colder microhabitats. Because thermal properties such as increased insulation accompany the winter white molt (Walsberg 1991; Sheriff et al. 2009), molting hares may prefer colder areas when ambient temperatures are warm. In addition to its effect on hare resting site selection, temperature may also have a weak influence on hare molt phenology (Watson 1963; Nagorsen 1983; Zimova et al. 2014, 2020a; Kumar 2015). Field-based tests of the direct effects of temperature on coat color molt are not yet possible due to the absence of a physiologically based connection between the trait and a relevant temperature metric (e.g., daily mean temperature, monthly maximum temperature, number of days above freezing, etc.) or appropriate temporal window.

Might the plasticity in both the initiation and rate of the molt provide a means for adaptive rescue if hare populations begin to decline due to increased mismatch resulting from shortening snow seasons? The observed difference in spring snow duration between 2013 and 2014 was approximately 20 days. This is less than the 29-35-day reduction in snow duration predicted in this area by mid-century, under either the medium-low or high greenhouse gas concentration scenarios, respectively (Mills et al. 2013). Although the mean population molt phenology (initiation and rate of molt) shifted in the direction of the rapid 2013 snowmelt, we nevertheless detected white hare mismatch in $23 \%$ of our observations (Fig. 4a), contrasted with just $2 \%$ of observations in 2014 (Fig. 4b). Moreover, analysis of raw data from a previously published study (Mills et al. 2013) revealed white hare mismatch in $15 \%$ of observations from an early snowmelt year (2010) compared to just $1 \%$ of the observations in the later snowmelt year (2011). In short, we find no evidence that snow-driven plasticity in molt phenology will prevent increased mismatch under reduced snow duration. Therefore, phenotypic plasticity in hare molt phenology is unlikely to facilitate adaptive rescue, a finding consistent with other studies that find phenotypic plasticity insufficient to enable long-term species persistence under climate change (e.g., Davis et al. 2017; Schmaljohann and Both 2017; Radchuk et al. 2019).

The extent to which phenotypic plasticity in molt phenology is driven by snow in the other 20 color molting species is unknown. However, the effects of extrinsic factors on molt phenology are similar in other mammalian color molting species (Zimova et al. 2018). Therefore, it is possible that snow plays a mediating role across taxa, although sympatric interspecific differences in molt phenology do occur (Davis et al. 2019). In addition to color molting species, snow has also been shown to affect other phenological processes across diverse taxa. For example, in both Columbian and Arctic ground squirrels, hibernation emergence is influenced by snow cover (Sheriff et al. 2011; Lane et al. 2012). Likewise, snow melt drives the onset of vegetative growth, (Inouye et al. 2000) and the seasonal migration patterns of elk (Rickbeil et al. 2019). Finally, snow melt was the most important predictor explaining clutch initiation advancement for arctic shorebird and passerine species, explaining more variation in phenology than green-up (Liebezeit et al. 2014). Thus, snow-mediated plasticity in phenological processes appears to be more common than previously expected.

Although the scope of our inference strictly applies to only snowshoe hares in western Montana, it builds on a substantial body of work establishing this species as a powerful model system to reveal general principles for how species might adapt to climate change (e.g., Jones et al. 2018, 2020a, b, Mills et al. 2013, 2018; Sultaire et al. 2016; Wilson et al. 2018; Zimova et al. 2020a, b). While we find for hares that persistence under rapid environmental change will likely depend less on phenotypic plasticity and more on the potential for evolutionary change, an urgent priority is to determine across all species the relative importance of these modes of adaptive rescue (Bay et al. 2017; Diamond et al. 2017; Manhard et al. 2017; Mills et al. 2018).

Acknowledgements Financial support to A.V.K. came from National Science Foundation (NSF) Graduate Research Fellowship (DGE1252376) and "onXmaps". L.S.M. acknowledges the United States Bureau of Land Management - Missoula Field Office, the National Science Foundation EPSCoR Award No. 1736249 and the National Science Foundation Division of Environmental Biology grant no. 0841884 . M.Z. was supported by the Department of the Interior Southeast Climate Science Adaptation Centers (Global Change Fellowship through Cooperative Agreement No. G10AC00624) and the University of Montana. We thank all the volunteers and assistants who 
helped with the fieldwork and data management especially Tucker Seitz as well as the University of Montana and North Carolina State University. Kevin Gross provided statistical guidance. Roland Kays, Beth Gardner, Kara Dziwulski, Kevin McKelvey, Diana Lafferty, and Nathan Hostetter provided helpful feedback on earlier drafts. The authors have no competing interests to declare.

Author contribution statement AK, SM, JS conceived and designed the research; AK, MZ analyzed the data; AK, SM, MZ, JS wrote and edited the manuscript.

Data availability The data reported in the paper are archived in the Dryad Digital Repository at https://doi.org/10.5061/dryad.7d7wm37s8.

Open Access This article is licensed under a Creative Commons Attribution 4.0 International License, which permits use, sharing, adaptation, distribution and reproduction in any medium or format, as long as you give appropriate credit to the original author(s) and the source, provide a link to the Creative Commons licence, and indicate if changes were made. The images or other third party material in this article are included in the article's Creative Commons licence, unless indicated otherwise in a credit line to the material. If material is not included in the article's Creative Commons licence and your intended use is not permitted by statutory regulation or exceeds the permitted use, you will need to obtain permission directly from the copyright holder. To view a copy of this licence, visit http://creativecommons.org/licenses/by/4.0/.

\section{References}

Adams L (1959) An analysis of a population of snowshoe hares in Northwestern Montana. Ecol Monogr 29:141-170

Atmeh K, Andruszkiewicz A, Zub K (2018) Climate change is affecting mortality of weasels due to camouflage mismatch. Sci Rep 8:7648. https://doi.org/10.1038/s41598-018-26057-5

Bates D, Mächler M, Bolker B, Walker S (2015) Fitting linear mixedeffects models using lme4. J Stat Softw 67:1-48. https://doi. org/10.18637/jss.v067.i01

Bay RA, Rose NH, Logan CA, Palumbi SR (2017) Genomic models predict successful coral adaptation if future ocean warming rates are reduced. Sci Adv 3:e1701413

Beever EA, Hall LE, Varner J et al (2017) Behavioral flexibility as a mechanism for coping with climate change. Front Ecol Environ 15:299-308. https://doi.org/10.1002/fee.1502

Bolker BM, Brooks ME, Clark CJ et al (2009) Generalized linear mixed models: a practical guide for ecology and evolution. Trends Ecol Evol 24:127-135. https://doi.org/10.1016/j.tree.2008.10.008

Both C, Visser ME (2001) Adjustment to climate change is constrained by arrival date in a long-distance migrant bird. Nature 411:296-298

Burt DM, Roloff GJ, Etter DR (2017) Climate factors related to localized changes in snowshoe hare (Lepus americanus) occupancy. Can J Zool 95:15-22

Choi G, Robinson DA, Kang S (2010) Changing Northern Hemisphere snow seasons. J Clim 23:5305-5310. https://doi. org/10.1175/2010JCLI3644.1

Cohen JM, Lajeunesse MJ, Rohr JR (2018) A global synthesis of animal phenological responses to climate change. Nat Clim Change 8:224-228. https://doi.org/10.1038/s41558-018-0067-3

Davis CL, Miller DAW, Walls SC et al (2017) Life history plasticity does not confer resilience to environmental change in the mole salamander (Ambystoma talpoideum). Oecologia 183:739-749. https://doi.org/10.1007/s00442-017-3810-y
Davis BM, Kumar AV, Mills LS (2019) A camouflage conundrum: unexpected differences in winter coat color between sympatric species. Ecosphere 10:e02658. https://doi.org/10.1002/ecs2.2658

Diamond SE, Chick L, Perez A et al (2017) Rapid evolution of ant thermal tolerance across an urban-rural temperature cline. Biol J Linn Soc 121:248-257

Diefenbach DR, Rathbun SL, Vreeland JK et al (2016) Evidence for range contraction of snowshoe hare in Pennsylvania. Northeast Nat 23:229-248. https://doi.org/10.1656/045.023.0205

Dormann CF, Elith J, Bacher S et al (2013) Collinearity: a review of methods to deal with it and a simulation study evaluating their performance. Ecography (Cop) 36:027-046. https://doi.org/10 $.1111 / \mathrm{j} .1600-0587.2012 .07348 . x$

Ferron J, Ouellet J-P (1992) Daily partitioning of summer habitat and use of space by the snowshoe hare in Southern Boreal Forest. Can J Zool 70:2178-2183

Flux JEC (1970) Colour change of mountain hares (Lepus timidus scoticus) in North-East Scotland. J Zool 162:345-358

Forsman A (2015) Rethinking phenotypic plasticity and its consequences for individuals, populations and species. Heredity (Edinb) 115:276-284. https://doi.org/10.1038/hdy.2014.92

Ghalambor CK, Martin TE (2001) Fecundity-survival trade-offs and parental risk-taking in birds. Science 292(80):494-497. https:// doi.org/10.1126/science.1059379

Gienapp P, Teplitsky C, Alho JS et al (2008) Climate change and evolution: disentangling environmental and genetic responses. Mol Ecol 17:167-178. https://doi.org/10.1111/j.1365294X.2007.03413.x

Gigliotti LC, Diefenbach DR (2018) Risky behavior and its effect on survival: snowshoe hare behavior under varying moonlight conditions. J Zool. https://doi.org/10.1111/jzo.12532

Gilbert BS, Boutin S (1991) Effect of moonlight on winter activity of showshoe hares. Arct Antarct Alp Res 23:61-65

Goldman BD (2001) Mammalian photoperiodic system: formal properties and neuroendocrine mechanisms of photoperiodic time measurement. J Biol Rhythms 16:283-301. https://doi. org/10.1177/074873001129001980

Goodrich LE (1982) The influence of snow cover on the ground thermal regime. Can Geotech J 19:421-432

Grange WB (1932) The pelages and color changes of the snowshoe hare, Lepus americanus phaeonotus, Allen. J Mammal 13:99-116

Griffin PC, Griffin SC, Waroquiers C, Mills LS (2005) Mortality by moonlight: predation risk and the snowshoe hare. Behav Ecol 16:938-944. https://doi.org/10.1093/beheco/ari074

Hock R, Rasul G, Adler C et al (2019) High mountain areas. In: Pörtner HO, Roberts DC, Masson-Delmotte V et al (eds) IPCC special report on the ocean and cryosphere in a changing climate, $p p$ 131-202 (in press)

Hodges KE (2000) The ecology of snowshoe hares in Northern Boreal Forests. In: Ecology and conservation of Lynx in the United States. University Press of Colorado, Boulder, CO, pp 117-161

Hoffmann AA, Sgró CM (2011) Climate change and evolutionary adaptation. Nature 470:479-485. https://doi.org/10.1038/nature09670

Inouye DW, Barr B, Armitage KB, Inouye BD (2000) Climate change is affecting altitudinal migrants and hibernating species. Proc Natl Acad 97:1630-1633. https://doi.org/10.1073/pnas.97.4.1630

Ivan JS, Shenk TM (2016) Winter diet and hunting success of Canada Lynx in Colorado. J Wildl Manag 80:1049-1058. https://doi. org/10.1002/jwmg. 21101

Jackes AD, Watson A (1975) Winter whitening of Scottish Mountain hares (Lepus timidus scoticus) in relation to day length, temperature and snow-lie. J Zool 176:403-409

Jones MR, Mills LS, Alves PC et al (2018) Adaptive introgression underlies polymorphic seasonal camouflage in snowshoe hares. Science 360(80):1355-1358 
Jones MR, Mills LS, Jensen JD, Good JM (2020a) Convergent evolution of seasonal camouflage in response to reduced snow cover across the snowshoe hare range. Evolution. https://doi. org/10.1111/evo.13976

Jones MR, Mills LS, Jensen JD, Good JM (2020b) The origin and spread of locally adaptive seasonal camouflage in snowshoe hares. Am Nat. https://doi.org/10.1086/710022

Kudo G, Ida TY (2013) Early onset of spring increases the phenological mismatch between plants and pollinators. Ecology 94:23112320. https://doi.org/10.1890/12-2003.1

Kumar AV (2015) Effects of a dynamic forest structure on vital rates, behavior and the seasonal molt of the snowshoe hare. North Carolina State University, Raleigh

Kumar AV, Sparks JR, Mills LS (2018) Short-term response of snowshoe hares to western larch restoration and seasonal needle drop. Restor Ecol 26:156-164. https://doi.org/10.1111/rec.12533

Kunkel KE, Robinson DA, Champion S et al (2016) Trends and extremes in Northern Hemisphere snow characteristics. Curr Clim Chang Rep 2:65-73. https://doi.org/10.1007/s4064 1-016-0036-8

Lane JE, Kruuk LEB, Charmantier A et al (2012) Delayed phenology and reduced fitness associated with climate change in a wild hibernator. Nature 489:554-557. https://doi.org/10.1038/ nature 11335

Lewis CW, Hodges KE, Koehler GM, Mills LS (2011) Influence of stand and landscape features on snowshoe hare abundance in fragmented forests. J Mammal 92:561-567. https://doi. org/10.1644/10-MAMM-A-095.1

Liebezeit JR, Gurney KEB, Budde M et al (2014) Phenological advancement in arctic bird species: relative importance of snow melt and ecological factors. Polar Biol 37:1309-1320. https://doi. org/10.1007/s00300-014-1522-x

Litvaitis JA (1991) Habitat use by snowshoe hares, Lepus americanus, in relation to pelage color. Can Field-Nat 105:275-277

Litvaitis JA, Sherburne JA, Bissonette JA (1985) Influence of understory characteristics on snowshoe hare habitat use and density. J Wildl Manag 49:866-873

Lyman CP (1943) Control of coat color in the varying hare Lepus americanus Erxleben. Bull Mus Comp Zool Harvard Univ 93:391-461

Manhard CV, Joyce JE, Gharrett AJ (2017) Evolution of phenology in a salmonid population: a potential adaptive response to climate change. Can J Fish Aquat Sci 74:1519-1527

Mills LS, Zimova M, Oyler J et al (2013) Camouflage mismatch in seasonal coat color due to decreased snow duration. Proc Natl Acad Sci 110:7360-7365. https://doi.org/10.1073/pnas.1222724110

Mills LS, Bragina EV, Kumar AV et al (2018) Winter color polymorphisms identify global hot spots for evolutionary rescue from climate change. Science 359(80):1033-1036. https://doi. org/10.1126/science.aan8097

Nagorsen DW (1983) Winter pelage colour in snowshoe hares (Lepus americanus) from the Pacific Northwest. Can J Zool 61:2313-2318

Namias J (1985) Some empirical evidence for the influence of snow cover on temperature and precipitation. Mon Weather Rev 113:1542-1553

Ozgul A, Childs DZ, Oli MK et al (2010) Coupled dynamics of body mass and population growth in response to environmental change. Nature 466:482-485. https://doi.org/10.1038/nature09210

Parmesan C (2007) Influences of species, latitudes and methodologies on estimates of phenological response to global warming. Glob Chang Biol 13:1860-1872. https://doi.org/10.111 1/j.1365-2486.2007.01404.x

Pauli JN, Zuckerberg B, Whiteman JP, Porter W (2013) The subnivium: a deteriorating seasonal refugium. Front Ecol Environ 11:260 267. https://doi.org/10.1890/120222
Pederson GT, Gray ST, Woodhouse CA et al (2011) The unusual nature of recent snowpack declines in the North American Cordillera. Science 333(80):332-335. https://doi.org/10.1126/science.12015 70

Penuelas J, Filella I, Zhang X et al (2012) Complex spatiotemporal phenological shifts as a response to rainfall changes. New Phytol 161:837-846. https://doi.org/10.1111/j.1469-8137.2003.01003.x

Przybylo R, Sheldon BC, Merila J (2000) Climatic effects on breeding and morphology: evidence for phenotypic plasticity. J Anim Ecol 69:395-403

Radchuk V, Reed T, Teplitsky C et al (2019) Adaptive responses of animals to climate change are most likely insufficient. Nat Commun 10:1-14. https://doi.org/10.1038/s41467-019-10924-4

R Development Core Team (2012) R version 2.15.1. R: a language and environment for statistical computing. R Foundation for Statistical Computing, Vienna, Austria

Rickbeil GJM, Merkle JA, Anderson G et al (2019) Plasticity in elk migration timing is a response to changing environmental conditions. Glob Chang Biol 25:2368-2381. https://doi.org/10.1111/ gcb. 14629

Rothschild M (1942) Change of pelage in the stoat Mustela erminea L. Nature 149:78

Rust CC (1962) Temperature as a modifying factor in the spring pelage change of short-tailed weasels. J Mammal 43:323-328

Schmaljohann H, Both C (2017) The limits of modifying migration speed to adjust to climate change. Nat Clim Change 7:573-576. https://doi.org/10.1038/NCLIMATE3336

Schwartz WJ, de la Iglesia HO, Zlomanczuk P, Illnerova H (2001) Encoding Le Quattro Stagioni within the mammalian brain: photoperiodic orchestration through the suprachiasmatic nucleus. J Biol Rhythms 16:302-311. https://doi.org/10.1177/0748730011 29002024

Sheriff MJ, Kuchel L, Boutin S, Humphries MM (2009) Seasonal metabolic acclimatization in a northern population of free-ranging snowshoe hares, Lepus americanus. J Mammal 90:761-767

Sheriff MJ, Kenagy GJ, Richter M et al (2011) Phenological variation in annual timing of hibernation and breeding in nearby populations of arctic ground squirrels. Proc R Soc B Biol Sci 278:23692375. https://doi.org/10.1098/rspb.2010.2482

Shipley AA, Sheriff MJ, Pauli JN, Zuckerberg B (2019) Snow roosting reduces temperature-associated stress in a wintering bird. Oecologia 190:309-321. https://doi.org/10.1007/s00442-019-04389-x

Snell-Rood EC, Kobiela ME, Sikkink KL, Shephard AM (2018) Mechanisms of plastic rescue in novel environments. Annu Rev Ecol Evol Syst 49:331-354

Steen JB, Erikstad KE, Høidal K (1992) Cryptic behaviour in moulting hen willow ptarmigan lagopus L. lagopus during snow melt. Ornis Scand 23:101-104

Stevens M, Ruxton GD (2019) The key role of behaviour in animal camouflage. Biol Rev 94:116-134. https://doi.org/10.1111/ brv. 12438

Sultaire SM, Pauli JN, Martin KJ et al (2016) Climate change surpasses land-use change in the contracting range boundary of a winter-adapted mammal. Proc R Soc B 283:20153104. https:// doi.org/10.1098/rspb.2015.3104

Vander Wal E, Garant D, Festa-Bianchet M, Pelletier F (2013) Evolutionary rescue in vertebrates: evidence, applications and uncertainty. Philos Trans R Soc B Biol Sci 368:20120090. https://doi. org/10.1098/rstb.2012.0090

Walsberg GE (1991) Thermal effects of seasonal coat change in three subarctic mammals. J Therm Biol 16:291-296

Watson A (1963) The effect of climate on the colour changes of mountain hares in Scotland. Proc Zool Soc Lond 141:823-835

Williams CM, Henry HAL, Sinclair BJ (2015) Cold truths: how winter drives responses of terrestrial organisms to climate change. Biol Rev 90:214-235. https://doi.org/10.1111/brv.12105 
Wilson EC, Shipley AA, Zuckerberg B et al (2018) An experimental translocation identifies habitat features that buffer camouflage mismatch in snowshoe hares. Conserv Lett. https://doi. org/10.1111/conl.12614

Wolff JO (1980) The role of habitat patchiness in the population dynamics of snowshoe hares. Ecol Monogr 50:111-130

Zhu L, Ives AR, Zhang C et al (2019) Climate change causes functionally colder winters for snow cover-dependent organisms. Nat Clim Change. https://doi.org/10.1038/s41558-019-0588-4

Zimova M, Mills LS, Lukacs PM, Mitchell MS (2014) Snowshoe hares display limited phenotypic plasticity to mismatch in seasonal camouflage. Proc R Soc B 281:20140029. https://doi.org/10.1098/ rspb.2014.0029

Zimova M, Mills LS, Nowak JJ (2016) High fitness costs of climate change-induced camouflage mismatch. Ecol Lett 19:299-307. https://doi.org/10.1111/ele.12568
Zimova M, Hackländer K, Good JM et al (2018) Function and underlying mechanisms of seasonal colour moulting in mammals and birds: what keeps them changing in a warming world? Biol Rev 93:1478-1498. https://doi.org/10.1111/brv.12405

Zimova M, Sirén APK, Nowak JJ et al (2020a) Local climate determines vulnerability to camouflage mismatch in snowshoe hares. Glob Ecol Biogeogr 29:503-515. https://doi.org/10.1111/ geb.13049

Zimova M, Barnard LS, Davis BM, Kumar AV, Lafferty DJR, Mills LS (2020b) Using remote cameras to measure seasonal molts. Ecosphere 11(4):e03084

\section{Affiliations}

\section{Alexander V. Kumar ${ }^{1,2}$ (D) $\cdot$ Marketa Zimova $^{3}$ D $\cdot$ James R. Sparks ${ }^{4} \cdot$ L. Scott Mills $s^{2,5}$}

1 Wildlife Biology Program, University of Montana, Missoula, MT 59812, USA

2 Department of Forestry and Environmental Resources, Program in Fisheries, Wildlife and Conservation Biology, North Carolina State University, Raleigh, NC 27695-7617, USA

3 School for Environment and Sustainability, University of Michigan, Ann Arbor, MI 49109, USA
4 Missoula Field Office, Bureau of Land Management, Missoula, MT 59804, USA

5 Wildlife Biology Program and Office of the Vice President for Research and Creative Scholarship, University of Montana, Missoula, MT 59812, USA 